\title{
Synthesis and Characterization of a Copper(II) Complex with 6-Hydroxypicolinic Acid and 3-Picoline ${ }^{\dagger}$
}

\author{
Boris-Marko Kukovec,* Matija Kakša, and Zora Popović* \\ Department of Chemistry, Faculty of Science, University of Zagreb, \\ Horvatovac 102a, 10000 Zagreb, Croatia
}

RECEIVED JUNE 12, 2012; REVISED OCTOBER 16, 2012; ACCEPTED OCTOBER 17, 2012

\begin{abstract}
A copper(II) complex with 6-hydroxypicolinic acid (6-OHpicH) and 3-picoline (3-pic), $\left[\mathrm{Cu}(6-\mathrm{OHpic})_{2}(3-\mathrm{pic})_{2}\right](\mathbf{1})$, was prepared by recrystallization of $\left[\mathrm{Cu}(6-\mathrm{OHpic})_{2}\left(\mathrm{H}_{2} \mathrm{O}\right)_{2}\right]$ from 3-picoline and characterized by IR spectroscopy and thermal methods (TGA/DTA and DSC). The molecular and crystal structure of $\mathbf{1}$ was determined by single-crystal X-ray structural analysis. The copper(II) ion in $\mathbf{1}$ has a tetragonally compressed octahedral coordination environment, achieved by two $\mathrm{N}, \mathrm{O}$-bidentate 6-hydroxypicolinate ligands and by two 3-picoline molecules in trans positions. The crystal structure of 1 exhibits one strong intermolecular $\mathrm{O}-\mathrm{H} \cdots \mathrm{O}$ hydrogen bond, one weak intermolecular $\mathrm{C}-\mathrm{H} \cdots \mathrm{O}$ hydrogen bond and one $\mathrm{C}-\mathrm{H} \cdots \pi$ interaction. Molecules of $\mathbf{1}$ are assembled into a 2D network in the $\left(\begin{array}{lll}1 & 0 & -1\end{array}\right)$ plane, giving rise to $\mathrm{C}_{1}^{1}(8)$ graph-set motif. These $2 \mathrm{D}$ networks are further assembled into $3 \mathrm{D}$ architecture only by weak Van der Waals interactions. A thermogravimetric study showed the initial loss of two coordinated 3-picoline molecules in $\mathbf{1}$, followed by a complete decomposition of the compound. (doi: $10.5562 / \mathrm{cca} 2119)$
\end{abstract}

Keywords: copper(II), 6-hydroxypicolinic acid, 3-picoline, crystal structure, thermal analysis (TGA/DTA, DSC), tetragonal compression

\section{INTRODUCTION}

Metal complexes of pyridine-2-carboxylic acid (picolinic acid, picH) have been widely studied as well as those of its derivatives with electron-withdrawing substituents, such as hydroxyl groups or halogen atoms, due to their great coordination flexibility and wide variety of physiological properties, especially insulinomimetic activity. ${ }^{1-7}$ Until now, there are only few reports regarding insulinomimetic properties of picolinate complexes bearing electron-donating groups such as a methyl group. ${ }^{3,8}$

Picolinate ligands favor the formation of mononuclear or polynuclear complexes due to their inherent tendency to form a chelate ring. They can also act as bridging ligands (up to four metal ions), ${ }^{9}$ thus offering a possibility of using them as building blocks to assemble multi-dimensional frameworks. Recently, we have explored the coordination modes of hydroxyl derivatives of picolinic acid towards the late 3d-block transition metals, namely cobalt(II), nickel(II) and copper(II)..$^{10-14}$
A lot of copper(II) complexes with picolinic acid derivatives and $N$-donor ligands (pyridine, 4-picoline, 3-picoline) are known from the literature. The pentacoordinated complexes $\left[\mathrm{Cu}(3-\mathrm{Mepic})_{2}(4-\mathrm{pic})\right],{ }^{15}$ $\left[\mathrm{Cu}(3-\mathrm{Mepic})_{2}(3\right.$-pic $\left.)\right],{ }^{16} \quad\left[\mathrm{Cu}(6-\mathrm{Mepic})_{2}(\text { py) }]^{17}\right.$ and $\left[\mathrm{Cu}(3-\mathrm{OHpic})_{2}(4-\mathrm{pic})\right]^{11}$ and octahedral complexes $\left[\mathrm{Cu}(3-\mathrm{OHpic})_{2}(3-\mathrm{pic})_{2}\right]^{14}$ and $\left[\mathrm{Cu}(6-\mathrm{OH} \text { pic })_{2}(4-\mathrm{pic})_{2}\right]^{11}$ were prepared by recrystallization of the initial complexes $\left[\mathrm{Cu}(3-\mathrm{Mepic})_{2}\left(\mathrm{H}_{2} \mathrm{O}\right)\right] \cdot \mathrm{H}_{2} \mathrm{O},{ }^{15,16} \quad\left[\mathrm{Cu}(6-\mathrm{Mepic})_{2}\right.$ $\left.\left(\mathrm{H}_{2} \mathrm{O}\right)\right],{ }^{17} \quad\left[\mathrm{Cu}(3-\mathrm{OHpic})_{2}\right]^{11}$ and $\left[\mathrm{Cu}(6-\mathrm{OHpic})_{2}\right.$ $\left.\left(\mathrm{H}_{2} \mathrm{O}\right)_{2}\right]^{11,18}$ from the corresponding solvents (pyridine, 4-picoline, 3-picoline).

As a part of our continuing interest in copper(II) complexes with molecules of biological importance, we have prepared a copper(II) complex with 6-hydroxypicolinic acid (6-OHpicH) and 3-picoline (3-pic), $\left[\mathrm{Cu}(6-\mathrm{OHpic})_{2}(3-\mathrm{pic})_{2}\right](\mathbf{1})$. The complex was characterized by IR spectroscopy and thermal methods (TGA/DTA, DSC) and its molecular and crystal structure was determined by single-crystal X-ray structural analysis.

\footnotetext{
$\dagger$ This article belongs to the Special Issue devoted to the $85^{\text {th }}$ anniversary of Croatica Chemica Acta.

* Authors to whom correspondence should be addressed. (E-mail: bkukovec@chem.pmf.hr, zpopovic@chem.pmf.hr)
} 


\section{EXPERIMENTAL}

\section{Materials and Physical Measurements}

All chemicals were of reagent grade, purchased from commercial sources and used as received, without further purification.

$\mathrm{CHN}$ analyses were performed by a Perkin-Elmer 2400 Series II CHNS analyzer in the Analytical Services Laboratories of the Ruđer Bošković Institute, Zagreb, Croatia.

The IR spectra were obtained from $\mathrm{KBr}$ pellets in the range $4000-450 \mathrm{~cm}^{-1}$ with a Perkin-Elmer Spectrum RXI FT-spectrometer.

TGA/DTA measurements were performed at heating rate of $5{ }^{\circ} \mathrm{C} \mathrm{min}^{-1}$ in the temperature range of $25-500{ }^{\circ} \mathrm{C}$, under nitrogen flow of $100 \mathrm{~mL} \mathrm{~min}^{-1}$ by a simultaneous TGA/DTA analyzer TA Instruments, Model SDT 2960. Approximately $10 \mathrm{mg}$ of sample were placed in an open aluminum crucible.

DSC measurements were performed at heating rate of $10{ }^{\circ} \mathrm{C} \mathrm{min}^{-1}$ in the temperature range of $25-$ $500{ }^{\circ} \mathrm{C}$, under nitrogen flow of $200 \mathrm{~mL} \mathrm{~min}{ }^{-1}$ by a Mettler-Toledo DSC $823^{\mathrm{e}}$ instrument. Approximately $5 \mathrm{mg}$ of sample were placed in closed aluminum crucible $(40 \mu \mathrm{L})$.

\section{Synthesis of $\left[\mathrm{Cu}(6-\mathrm{OHpic})_{2}(3-\mathrm{pic})_{2}\right]$ (1)}

A 3-picoline solution $(5 \mathrm{~mL})$ of $\left[\mathrm{Cu}(6-\mathrm{OHpic})_{2}\left(\mathrm{H}_{2} \mathrm{O}\right)_{2}\right]^{11}$ $(0.19 \mathrm{~g}, 0.51 \mathrm{mmol})$ was left to stand at room temperature to slowly evaporate. The blue crystals, suitable for $\mathrm{X}$-ray crystal structure analysis, were formed in ten days. The crystals were filtered off, washed with the mother liquor and dried in vacuo. Yield: $0.13 \mathrm{~g}(48 \%)$. Anal. Calcd. mass fractions of elements, $w / \%$, for $\mathrm{C}_{24} \mathrm{H}_{22} \mathrm{CuN}_{4} \mathrm{O}_{6}\left(M_{\mathrm{r}}=526.01\right): \mathrm{C}, 54.80 ; \mathrm{H}, 4.22 ;$ $\mathrm{N}, 10.65$. Found: C, 54.67; H, 4.51; N, 10.27. IR ( $\mathrm{KBr}$ pellets) $v / \mathrm{cm}^{-1}: 1668 \mathrm{~s}, 1617 \mathrm{~s}, 1576 \mathrm{~s}, 1483 \mathrm{~m}$, $1453 \mathrm{~s}, 1394 \mathrm{~s}, 1351 \mathrm{~m}, 1320 \mathrm{~s}, 1255 \mathrm{~s}, 1200 \mathrm{w}, 1151 \mathrm{~m}$, $1115 \mathrm{w}, 1073 \mathrm{~m}, 1020 \mathrm{~m}, 1001 \mathrm{w}, 969 \mathrm{w}, 827 \mathrm{~m}$, 801 m, 779 m, 748 m, 707 m, 659 m, 554 m, 479 m.

\section{Single Crystal X-ray Diffraction Analysis and Structure Determination}

A suitable single crystal of $\mathbf{1}$ was selected and mounted in air onto a thin glass fiber. The data collection for $\mathbf{1}$ was carried out by an Oxford Diffraction Xcalibur fourcircle kappa geometry diffractometer with Xcalibur Sapphire 3 CCD detector, using a graphite monochromated $\operatorname{MoK}_{\alpha}(\lambda=0.71073 \AA)$ radiation, and by applying the CrysAlis Software system, Version 171.32.29 at room temperature (296(2) K). Data reduction was done by the same program. ${ }^{19}$

The X-ray diffraction data were corrected for Lorentz-polarization factor and scaled for absorption effects by evaluation of multi-scans. The structure was solved by direct methods implemented in SHELXS97. ${ }^{20}$ A refinement procedure by full-matrix leastsquares methods, based on $F^{2}$ values against all reflections, was performed by SHELXL- $97,{ }^{20}$ including anisotropic displacement parameters for all non- $\mathrm{H}$ atoms.

The position of hydrogen atoms belonging to the carbon atoms $\mathrm{Csp}^{2}$ and $\mathrm{Csp}^{3}$ and to the hydroxyl $\mathrm{O}$ atom were geometrically optimized applying the riding model $\left(\mathrm{Csp}^{2}-\mathrm{H}, 0.93 \AA, U_{\text {iso }}(\mathrm{H})=1.2 U_{\text {eq }}(\mathrm{C}) ; \mathrm{Csp}^{3}\right.$ (methyl) $-\mathrm{H}$, $0.96 \AA, U_{\text {iso }}(\mathrm{H})=1.5 U_{\text {eq }}(\mathrm{C}) ; \mathrm{O}-\mathrm{H}, 0.82 \AA, U_{\text {iso }}(\mathrm{H})=$ $\left.1.5 U_{\text {eq }}(\mathrm{O})\right)$.

The calculations concerning the molecular geometry, the choice and verification of the space group, the analysis of hydrogen bonds and $\mathrm{C}-\mathrm{H} \cdots \pi$ interactions

Table 1. The crystal data and details of the structure refinement for 1

\begin{tabular}{|c|c|}
\hline Formula & $\mathrm{C}_{24} \mathrm{H}_{22} \mathrm{CuN}_{4} \mathrm{O}_{6}$ \\
\hline$M_{\mathrm{r}}$ & 526.01 \\
\hline Color and habit & green, prism \\
\hline Crystal system & monoclinic \\
\hline Space group & $P 2_{1} / n$ \\
\hline Crystal dimensions $/ \mathrm{mm}^{3}$ & $0.76 \times 0.53 \times 0.36$ \\
\hline$a / \AA$ & $9.5380(2)$ \\
\hline$b / \AA$ & $8.49410(10)$ \\
\hline$c / \AA$ & $14.8021(3)$ \\
\hline$\beta /{ }^{\circ}$ & $105.0677(19)$ \\
\hline$V / \AA^{3}$ & $1157.99(4)$ \\
\hline$Z$ & 2 \\
\hline$D_{\text {calc }} / \mathrm{g} \mathrm{cm}^{-3}$ & 1.509 \\
\hline$\mu / \mathrm{mm}^{-1}$ & 0.992 \\
\hline$F(000)$ & 542 \\
\hline$\theta$ range for data collection $/{ }^{\circ}$ & $3.94-30.00$ \\
\hline$h, k, l$ range & $\begin{array}{l}-13: 13,-11: 11 \\
-20: 20\end{array}$ \\
\hline Scan type & $\omega, \varphi$ \\
\hline Number of measured reflections & 21752 \\
\hline $\begin{array}{l}\text { Number of independent reflections } \\
\left(R_{\text {int }}\right)\end{array}$ & $3345(0.0211)$ \\
\hline $\begin{array}{l}\text { Number of observed reflections, } \\
I \geq 2 \sigma(I)\end{array}$ & 2505 \\
\hline Number of refined parameters & 162 \\
\hline$R^{(\mathrm{a})}, w R^{(\mathrm{b})}[I \geq 2 \sigma(I)]$ & $0.0298,0.0823$ \\
\hline$R, w R$ [all data] & $0.0432,0.0855$ \\
\hline Goodness of fit on $F^{2}, S^{(c)}$ & 0.996 \\
\hline Max. and min. electron density / e $\AA^{-3}$ & $0.47,-0.20$ \\
\hline
\end{tabular}


were performed by PLATON. ${ }^{21}$ The molecular graphics were done with ORTEP- $3^{22}$ and MERCURY (Version $3.0){ }^{23}$

The crystal parameters, data collection and refinement results for $\mathbf{1}$ are summarized in Table 1.

\section{RESULTS AND DISCUSSION}

\section{Chemical Studies}

Complex $\left[\mathrm{Cu}(6-\mathrm{OHpic})_{2}(3-\mathrm{pic})_{2}\right]$ (1) was prepared by recrystallization of $\left[\mathrm{Cu}(6-\mathrm{OHpic})_{2}\left(\mathrm{H}_{2} \mathrm{O}\right)_{2}\right]$ from 3-picoline. The initial complex $\left[\mathrm{Cu}(6-\mathrm{OHpic})_{2}\left(\mathrm{H}_{2} \mathrm{O}\right)_{2}\right]$ was prepared by the reaction of copper(II) sulfate pentahydrate and 6-hydroxypicolinic acid in the acidic aqueous solution ( $\mathrm{pH}$ 1). ${ }^{11}$ The coordinated $\mathrm{H}_{2} \mathrm{O}$ molecules in $\left[\mathrm{Cu}(6-\mathrm{OH} \text { pic })_{2}\left(\mathrm{H}_{2} \mathrm{O}\right)_{2}\right]$ could be substituted by the 3-picoline molecules during its dissolution in 3 -picoline, leading to the formation of $\mathbf{1}$. Complex 1 decomposes by prolonged standing in air due to release of coordinated 3-picoline molecules. It is soluble in solvents with pronounced donor properties, such as $N, N$-dimethyl-formamide, dimethylsulfoxide, pyridine and 3-picoline.

\section{Crystal Structure}

An ORTEP-3 view of the molecular structure of 1 is depicted in Figure 1 and its crystal structure in Figure 2. The selected molecular geometry parameters are listed in Table 2 and the hydrogen bond geometry in Table 3.

The coordination environment of the copper(II) ion in $\mathbf{1}$ can be described as a distorted octahedron, revealing tetragonal compression due to the Jahn-Teller effect. The copper(II) ion in $\mathbf{1}$ is situated on a crystallo-

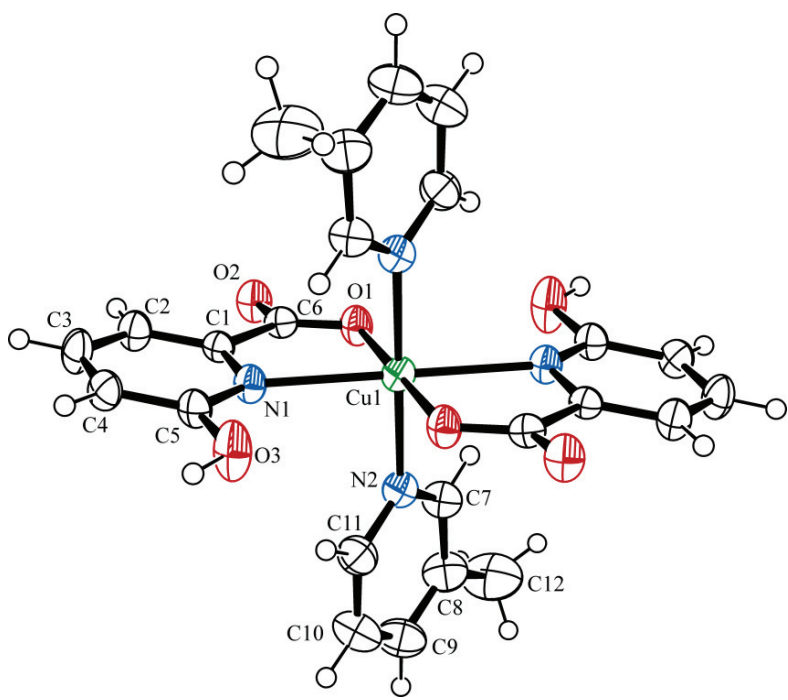

Figure 1. An ORTEP-3 drawing of 1 with the atomic numbering scheme of the asymmetric unit. The thermal ellipsoids are drawn at the $50 \%$ probability level at 296(2) K. graphic inversion center and it is coordinated by two 6-hydroxypicolinate ligands in the equatorial plane and by two 3-picoline molecules in the axial positions. The 6-hydroxypicolinate ligands are bound to a copper(II) ion in a bidentate $\mathrm{N}, \mathrm{O}$-chelated mode, forming fivemembered rings (Figure 1). The Cu1-N2 bond distance of 2.031(1) $\AA$ is significantly shorter than the Cu1-N1 bond distance of 2.328(1) $\AA$, in accordance with the Jahn-Teller effect typical for $\mathrm{d}^{9}$ electron configuration. $\mathrm{The} \mathrm{Cu}-\mathrm{N}$ and $\mathrm{Cu}-\mathrm{O}$ bond distances $(\mathrm{N}$ and $\mathrm{O}$ atoms from 6-hydroxypicolinate) in $\mathbf{1}$ (Table 2) are longer than the corresponding ones reported in the literature for copper(II) complexes with picolinic, ${ }^{24-26} 3$-hydroxypicolinic, ${ }^{11,14,27,28}$ 6-hydroxypicolinic, ${ }^{11,18,29}$ 3-methylpicolinic, ${ }^{15,16} 6$-methylpicolinic ${ }^{17}$ and 6-bromopicolinic acid. $^{17}$

The bond angles around the copper(II) ion, involving trans pairs of donor atoms, are exactly $180^{\circ}$ due to the symmetry. The distortion of the octahedron is indicated by the angles with values from $76.37(4)^{\circ}$ to 103.63(4) $)^{\circ}$ for cis pairs of ligating atoms. One of the angles indicating the largest distortion from the ideal octahedral geometry is the bite angle $\mathrm{O} 1-\mathrm{Cu} 1-\mathrm{N} 1$ with the value of $76.37(4)^{\circ}$ (Table 2).

The pyridine ring (defined by $\mathrm{N} 1 / \mathrm{C} 1 / \mathrm{C} 2 / \mathrm{C} 3 / \mathrm{C} 4 /$ $\mathrm{C} 5$ atoms) is not perfectly coplanar with the chelated ring (defined by $\mathrm{N} 1 / \mathrm{C} 1 / \mathrm{C} 6 / \mathrm{O} 1 / \mathrm{Cu} 1$ atoms), as it is evident from the value of the dihedral angle between the mentioned rings $\left(9.19(6)^{\circ}\right)$.

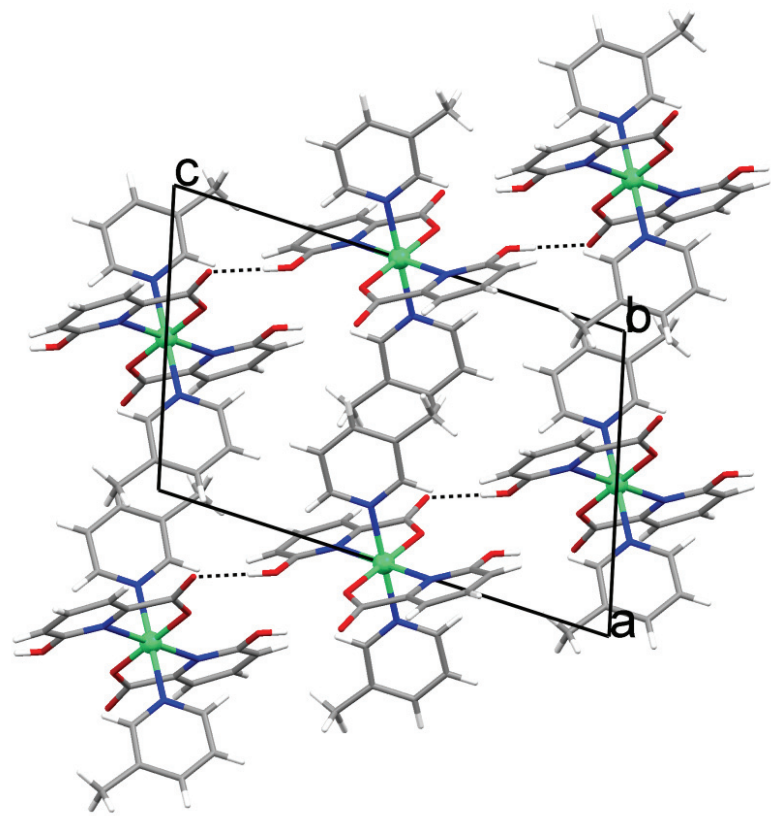

Figure 2. A view of the crystal structure of $\mathbf{1}$ in the $a c$ plane. Molecules are linked by intermolecular hydrogen bonds of the $\mathrm{O}-\mathrm{H} \cdots \mathrm{O}$ type (shown by the dotted lines) into a $2 \mathrm{D}$ network, which is represented as a linear chain in this projection. These linear chains extend along the [101] direction and are assembled together only by weak Van der Waals interactions. 
Table 2. The selected bond distances $(\AA)$ and angles $\left({ }^{\circ}\right)$ for $\mathbf{1}$

\begin{tabular}{lcc}
\hline \multicolumn{3}{c}{ Bond distances } \\
\hline $\mathrm{Cu} 1-\mathrm{O} 1$ & $2.015(1)$ \\
$\mathrm{Cu} 1-\mathrm{N} 1$ & $2.328(1)$ \\
$\mathrm{Cu} 1-\mathrm{N} 2$ & $2.031(1)$ \\
& & \\
$\mathrm{O} 1{ }^{i}-\mathrm{Cu} 1-\mathrm{O} 1$ & Bond angles & 180 \\
$\mathrm{O} 1-\mathrm{Cu} 1-\mathrm{N} 2$ & $89.38(4)$ \\
$\mathrm{O} 1-\mathrm{Cu} 1-\mathrm{N} 2^{i}$ & $90.62(4)$ \\
$\mathrm{N} 2^{i}-\mathrm{Cu} 1-\mathrm{N} 2$ & 180 \\
$\mathrm{O} 1^{i}-\mathrm{Cu} 1-\mathrm{N} 1$ & $103.63(4)$ \\
$\mathrm{O} 1-\mathrm{Cu} 1-\mathrm{N} 1$ & $76.37(4)$ \\
$\mathrm{N} 2{ }^{i}-\mathrm{Cu} 1-\mathrm{N} 1$ & $90.40(4)$ \\
$\mathrm{N} 2-\mathrm{Cu} 1-\mathrm{N} 1$ & $89.60(4)$ \\
$\mathrm{N} 1-\mathrm{Cu} 1-\mathrm{N} 1^{i}$ & & 180 \\
\hline
\end{tabular}

Symmetry code $(i): 1-x, 1-y,-z$

There are one intermolecular $\mathrm{O}-\mathrm{H} \cdots \mathrm{O}$ and two weak intermolecular $\mathrm{C}-\mathrm{H} \cdots \mathrm{O}$ hydrogen bonds in the crystal packing of $\mathbf{1}$. Hydroxyl $\mathrm{O} 3$ and pyridine $\mathrm{C} 4$ and C9 atoms act as proton donors, while both coordinated (O1 atom) and uncoordinated (O2 atom) caboxylate oxygen atoms act as proton acceptors in hydrogen bonding (Table 3). Molecules of $\mathbf{1}$ are assembled into a 2D network in the $(10-1)$ plane by intermolecular $\mathrm{O}-\mathrm{H} \cdots \mathrm{O}$ hydrogen bonds, giving rise to $\mathrm{C}^{1}{ }_{1}(8)$ graph-set motif. ${ }^{30}$ If it is viewed in the $a c$ plane, this network can be represented as a linear chain, extending along the [101] direction (Figure 2). These 2D networks are further assembled into 3D architecture only by weak Van der Waals interactions. There is also one $\mathrm{C}-\mathrm{H} \cdots \pi$ interaction $^{31}$ between the $\mathrm{C} 2$ atom and the pyridine ring defined by atoms $\mathrm{N} 2^{i} / \mathrm{C}^{i} / \mathrm{C} 8^{i} / \mathrm{C} 9^{i} / \mathrm{C} 10^{i} / \mathrm{C} 11^{i}$ (symmetry operator $(i): x, 1+y, z ; \mathrm{C} 2 \cdots \mathrm{cg}$ distance 3.592(2) $\AA$; $\mathrm{C} 2-\mathrm{H} 2 \cdots \mathrm{cg}$ angle $149^{\circ}$; $\mathrm{cg}=$ centroid of the ring) in the crystal structure of $\mathbf{1}$.

\section{IR Spectroscopy}

Infrared spectroscopy data confirm the coordination of the 6-hydroxypicolinate ligand to the copper(II) ion via carboxylate group in $\mathbf{1}$. In the spectrum of $\mathbf{1}$, the band associated to the antisymmetric stretching vibrational mode, $v_{\text {asym }}\left(\mathrm{COO}^{-}\right)$, appears at $1668 \mathrm{~cm}^{-1}\left(1700 \mathrm{~cm}^{-1}\right.$ in the uncoordinated ligand). The band associated to the symmetric stretching vibrational mode, $v_{\text {sym }}\left(\mathrm{COO}^{-}\right)$, appears at $1320 \mathrm{~cm}^{-1}\left(1295 \mathrm{~cm}^{-1}\right.$ in the uncoordinated ligand $)$. The value of $\Delta\left(v_{\text {asym }}\left(\mathrm{COO}^{-}\right)-v_{\text {sym }}\left(\mathrm{COO}^{-}\right)\right)$ amounts $348 \mathrm{~cm}^{-1}$, indicating the presence of carboxylate group coordinated to copper(II) ion in monodentate mode ${ }^{32,33}$ which is in agreement with the crystal structure of $\mathbf{1}$. The typical stretching vibrational mode of substituted pyridines, $v(\mathrm{CN})$, appears for the uncoordinated 6-hydroxypicolinic acid at $1606 \mathrm{~cm}^{-1}$ and it is shifted for $11 \mathrm{~cm}^{-1}$ to higher wavenumbers in $\mathbf{1}$. This shift is in agreement with the $N, O$-chelation, involving the pyridine $\mathrm{N}$ atom of 6-hydroxypicolinate ligand.

\section{Thermal Analysis (TGA/DTA, DSC)}

Complex $\mathbf{1}$ is thermally stable up to approximately $60{ }^{\circ} \mathrm{C}$ and decomposes in two endothermic steps. Two 3-picoline molecules are evolved in the first step (observed weight loss $31.0 \%$, calculated $35.4 \%$ ), with two endothermic peaks in the DTA curve $\left(80.7^{\circ} \mathrm{C}\right.$ and $\left.97.4^{\circ} \mathrm{C}\right)$. The complex further decomposes in the second step, revealing the release of both 6-hydroxypicolinate ligands (observed weight loss $51.6 \%$, calculated $52.5 \%$ ), with two endothermic peaks $\left(352.1{ }^{\circ} \mathrm{C}\right.$ and $\left.363.5{ }^{\circ} \mathrm{C}\right)$. The remained residue of $17.4 \%$ (calculated $15.1 \%$ ) at $500^{\circ} \mathrm{C}$ is most probably $\mathrm{CuO}$.

The DSC curve of $\mathbf{1}$ also shows two endothermic peaks for each of the two decomposition steps, similar as the DTA curve. Two peaks at $104.8^{\circ} \mathrm{C}$ and $116.9^{\circ} \mathrm{C}$ (80.7 ${ }^{\circ} \mathrm{C}$ and $97.4^{\circ} \mathrm{C}$ in the DTA curve) in the first step indicate the release of two 3-picoline ligands, while the two peaks at $367.1{ }^{\circ} \mathrm{C}$ and $375.1{ }^{\circ} \mathrm{C}\left(352.1{ }^{\circ} \mathrm{C}\right.$ and $363.5^{\circ} \mathrm{C}$ in the DTA curve) in the second step correspond to the decomposition of both 6-hydroxypicolinate ligands. The peaks in the DSC curve are shifted by $10-25^{\circ} \mathrm{C}$ to higher temperatures if compared to the peaks in the DTA curve.

The existence of two peaks in DTA and DSC curves for each step suggests that both the release of 3-picoline molecules and the decomposition of 6-hydroxypicolinate ligands may be composed of two different processes. However, this was not confirmed by TGA analysis.

Table 3. The hydrogen bond geometry for 1

\begin{tabular}{cccccc}
\hline $\mathrm{D}-\mathrm{H} \cdots \mathrm{A}$ & $d(\mathrm{D}-\mathrm{H}) / \AA$ & $d(\mathrm{H} \cdots \mathrm{A}) / \AA$ & $d(\mathrm{D} \cdots \mathrm{A}) / \AA$ & $\angle(\mathrm{D}-\mathrm{H} \cdots \mathrm{A}) /{ }^{\circ}$ & Symmetry code on A \\
\hline $\mathrm{O} 3-\mathrm{H} 13 \mathrm{O} \cdots \mathrm{O} 2$ & 0.82 & 1.78 & $2.584(1)$ & 167 & $1 / 2+x, 3 / 2-y, 1 / 2+z$ \\
$\mathrm{C} 4-\mathrm{H} 4 \cdots \mathrm{O} 1$ & 0.93 & 2.54 & $3.376(2)$ & 149 & $1 / 2+x, 3 / 2-y, 1 / 2+z$ \\
$\mathrm{C} 9-\mathrm{H} 9 \cdots \mathrm{O} 2$ & 0.93 & 2.58 & $3.476(2)$ & 161 & $-x, 1-y,-z$ \\
\hline
\end{tabular}




\section{CONCLUSION}

The copper(II) ion in $\mathbf{1}$ is octahedrally coordinated by two $\mathrm{N}, \mathrm{O}$-bidentate 6-hydroxypicolinate ligands and two 3-picoline molecules in trans position, revealing a tetragonal compression of the octahedron due to the JahnTeller effect. This is the first example of tetragonal compression found in octahedral copper(II) complexes with picolinic acid derivatives. Other related octahedral copper(II) complexes with 3-hydroxypicolinic and 6-hydroxypicolinic acid (e.g. $\left[\mathrm{Cu}(6-\mathrm{OHpic})_{2}\left(\mathrm{H}_{2} \mathrm{O}\right)_{2}\right]{ }^{18}$ $\left[\mathrm{Cu}(6-\mathrm{OHpic})_{2}(4-\mathrm{pic})_{2}\right]^{11}$ and $\left.\left[\mathrm{Cu}(3-\mathrm{OHpic})_{2}(3-\mathrm{pic})_{2}\right]^{14}\right)$ exhibit a tetragonally elongated copper(II) octahedron.

Supplementary Materials. - CCDC 885975 contains the supplementary crystallographic data for this paper and can be obtained free of charge via www.ccdc.cam.ac.uk/data_request/cif [or from the Cambridge Crystallographic Data Centre (CCDC), 12 Union Road, Cambridge CB2 1EZ, UK; fax: +44(0)1223-336033; email: deposit@ccdc.cam.ac.uk]. The structure factor table is available from the authors.

Acknowledgements. This research was supported by the Ministry of Science, Education and Sports of the Republic of Croatia (Grant No. 119-1193079-1332). The authors thank Dr. Sanja Matečić Mušanić from Brodarski Institute, Zagreb, Croatia for TGA/DTA measurements.

\section{REFERENCES}

1. A. Shaver, J. B. Ng, D. A. Hall, B. S. Lum, and B. I. Posner, Inorg. Chem. 32 (1993) 3109-3113.

2. H. Sakurai, K. Fujii, H. Watanabe, and H. Tamura, Biochem. Biophys. Res.Commun. 214 (1995) 1095-1101.

3. H. Sakurai, A. Tamura, T. Takino K. Ozutsumi, K. Kawabe, and Y. Koyima, Inorg. React. Mech. 2 (2000) 69-77.

4. K. H. Thompson and C. Orvig, J. Chem. Soc., Dalton Trans. (2000) 2885-2892.

5. E. Kiss, A. Bényei, and T. Kiss, Polyhedron 22 (2003) 27-33.

6. M. Nakai, M. Obata, F. Sekiguchi, M. Kato, M. Shiro, A. Ichimura, I. Kinoshita, M. Mikuriya, T. Inohara, K. Kawabe, H. Sakurai, C. Orvig, and S. Yano, J. Inorg. Biochem. 98 (2004) 105-112.

7. M. Nakai, F. Sekiguchi, M. Obata, C. Ohtsuki, Y. Adachi, H. Sakurai, C. Orvig, D. Rehder, and S. Yano, J. Inorg. Biochem. 99 (2005) 1275-1282.

8. Y. Yoshikawa, E. Ueda, K. Kawabe, H. Miyake, T. Takino, H. Sakurai, and Y. Kojima, J. Biol. Inorg. Chem. 7 (2002) 68-73.
9. R. A. Coxall, S. G. Harris, D. K. Henderson, S. Parsons, P. A. Tasker, and R. E. P. Winpenny, J. Chem. Soc. Dalton Trans. (2000) 2349-2356.

10. B.-M. Kukovec, Z. Popović, G. Pavlović, and M. Rajić Linarić, J. Mol. Struct. 882 (2008) 47-55.

11. B.-M. Kukovec, Z. Popović, and G. Pavlović, Acta. Chim. Slov. 55 (2008) 779-787.

12. B.-M. Kukovec, I. Kodrin, Z. Mihalić, K. Furić, and Z. Popović, Inorg. Chim. Acta 363 (2010) 1887-1896.

13. B.-M. Kukovec, P. D. Vaz, M. J. Calhorda, and Z. Popović, Cryst. Growth Des. 10 (2010) 3685-3693.

14. B.-M. Kukovec, P. D. Vaz, M. J. Calhorda, and Z. Popović, Polyhedron 39 (2012) 66-75.

15. B.-M. Kukovec, Z. Popović, and G. Pavlović, J. Coord. Chem. 61 (2008) 3092-3101.

16. B.-M. Kukovec, I. Kodrin, V. Vojković, and Z. Popović, Polyhedron (2012), in press

17. B.-M. Kukovec, Z. Popović, B. Kozlevčar, and Z. Jagličić, Polyhedron 27 (2008) 3631-3638.

18. A. Sengül and O. Büyükgüngör, Acta Crystallogr. C61 (2005) m119-m121.

19. Oxford Diffraction, CrysAlis CCD and CrysAlis RED, Version 171.32.29, Oxford Diffraction Ltd., Abingdon, Oxfordshire, England, 2008.

20. G. M. Sheldrick, Acta Crystallogr. A64 (2008) 112-122.

21. A. L. Spek, J. Appl. Crystallogr. 36 (2003) 7-13.

22. L. J. Farrugia, J. Appl. Crystallogr. 30 (1997) 565.

23. C. F. Macrae, I. J. Bruno, J. A. Chisholm, P. R. Edgington, P. McCabe, E. Pidcock, L. Rodriguez-Monge, R. Taylor, J. van de Streek, and P. A. Wood, J Appl Crystallogr. 41 (2008) 466-470.

24. B. Żurowska, J. Ochocki, J. Mroziński, Z. Ciunik, and J. Reedijk, Inorg. Chim. Acta 357 (2004) 755-763.

25. J. H. Luo, M. C. Hong, Q. Shi, Y. C. Liang, Y. J. Zhao, R. H. Wang, R. Cao, and J. B. Weng, Transition Met. Chem. 27 (2002) 311-315.

26. P. Segl'a, M. Jamnický, M. Koman, J. Šima, and T. Glowiak, Polyhedron 17 (1998) 4525-4533.

27. C. Sun, X. Zheng, and L. Jin, J. Mol. Struct. 646 (2003) 201210.

28. P. I. Girginova, F. A. A. Paz, H. I. S. Nogueira, N. J. O. Silva, V. S. M. Amaral, J. Klinowski, and T. Trindade, J. Mol. Struct. 737 (2005) 221-229.

29. C. Y. Sun, J. Zhou, W. J. Li, and L. P. Jin, Z. Anorg. Allg. Chem. 634 (2008) 549-554.

30. M. C. Etter, J. C. MacDonald, and J. Bernstein, Acta Crystallogr. B46 (1990) 256-262.

31. C. Janiak, J. Chem. Soc., Dalton Trans. (2000) 3885-3896.

32. G. B. Deacon and R. J. Phillips, Coord. Chem. Rev. 33 (1980) 227-250.

33. K. Nakamoto, Infrared and Raman Spectra of Inorganic and Coordination Compounds, Part B, 6th Edition, John Wiley \& Sons, Hoboken, 2009. 